\title{
A FRAMEWORK FOR IT PROJECT COMPLEXITY MANAGEMENT
}

\author{
Stefan Morcov ${ }^{1}$, Liliane Pintelon ${ }^{1} *$ and Rob J. Kusters ${ }^{2 *}$ \\ ${ }^{1}$ Katholieke Universiteit Leuven, Belgium \\ ${ }^{2}$ Open Universiteit Nederland, Netherlands \\ * Prof. Dr.
}

\begin{abstract}
Complexity is ubiquitous in modern IT engineering and project management. It is traditionally associated with risk and failure. But complexity also works: it delivers functionality, creativity, innovation. This paper proposes a conceptual framework to support IT Project Complexity Management in a structured, systematic way, consisting of the following processes: plan, identify, analyze, plan response strategies, monitor and control. The processes interact with each other and with other project management processes; they overlap, are incremental and iterative. They are described in terms of inputs and outputs, with a detailed inventory of available tools and techniques proposed for each process and step.
\end{abstract}

\section{KEYWORDS}

Project Management, Complexity, Complex Projects, Positive Complexity, Appropriate Complexity

\section{INTRODUCTION}

Contemporary IT projects are more and more challenging, larger, more complicated and complex. Project complexity is thus a topic of major interest in contemporary IT engineering.

Project complexity "makes it difficult to understand, foresee and manage a project's behavior, even when given reasonably complete information about the project system". It can be structural (i.e. consisting of many varied interrelated parts), or dynamic (i.e. referring to ambiguity, uncertainty, propagation, emergence, and chaos). Complexity strongly correlates with high cost, significant risk of failure, poor project management performance, and increased risk. Lack of understanding and recognition of system complexity is a critical cause of poor performance of large-scale IS/IT projects (Patanakul, 2014) (Montequín, et al., 2018) (Bjorvatn \& Wald, 2018) (Głodziński, 2019) (Morcov, et al., 2020a).

While complexity is traditionally regarded as negative, the benefits of technology to society and the economy are also significant. Complexity can have positive effects ("positive complexity"), or it can be appropriate (requisite). Positive and appropriate complexity are catalysts for opportunities (Maurer, 2017) (Morcov, et al., 2020b). A set of generic and specialized tools, guidelines, best practices, thumb rules are proposed by literature for managing project complexity (GAPPS, 2007) (PMI, 2013) (PMI, 2014) (Davies, et al., 2017) (Australian Government, Department of Defence, 2012) (Riis \& Pedersen, 2003) (Remington \& Pollack, 2007). Project managers currently apply these tools opportunistically - no structured approach being available (Botchkarev \& Finnigan, 2015).

This paper proposes a framework to support IT Project Complexity Management in a structured, systematic way. It is a conceptual framework, in which to anchor specific tools and techniques; a high-level process design that helps add structure to the management of complex IT projects, and systematize concepts and practical approach. Project Complexity Management thus becomes a knowledge area that includes specific processes to understand, plan strategy and responses, monitor and control project complexity. 


\section{METHODS}

The paper uses a qualitative approach based on design science, combined with a review of scientific literature related to IT project complexity management and management frameworks. Design science is a valid research methodology to develop solutions for practical engineering problems (Peffers, et al., 2007). Qualitative research helps develop initial understanding in a less explored area (Levitt, et al., 2018) (Gummesson, 2000).

The design of the management framework was based on a set of recognized management frameworks, including: project management, risk (PMI, 2017), vulnerability (Marle \& Vidal, 2016); problem-solving; system engineering complexity management (Maurer, 2017), OODA loop (observe, orient, decide, act) (Boyd, 2018), Systems development life cycle (SDLC); Waterfall software development methodology, Object-Oriented Analysis and Design (Satzinger, et al., 2007), Scrum Agile (Schwaber \& Sutherland, 2020), ADDIE and SAM models for instructional design (Allen \& Sites, 2012), PDCA/OPDCA management method (observe, plan, do, check, act) - the Deming Cycle (Liker \& Franz, 2011).

The inventory of tools and techniques was built based on a systematic literature review on project complexity. Systematic reviews are relevant methods for defining a framework of existing research, including gaps in existing research, in order to position and suggest future research (Kitchenham, 2004). The literature review used the search phrase: '(complex OR complexity) AND ("project management")', applied to the title and abstract on a large database of blind refereed research papers, extended by snowballing and additional areas such as Systems and IT Engineering (Morcov, et al., 2020a).

\section{PROCESSES, WITH INPUTS, OUTPUTS, TOOLS AND TECHNIQUES}

We define "Project Complexity Management" as the project management Knowledge Area that includes processes to understand, plan strategy and responses, and manage project complexity.

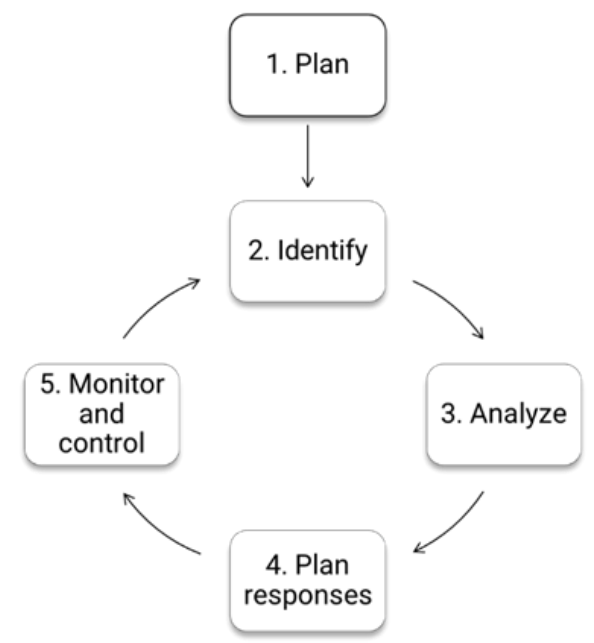

Figure 1. IT Project Complexity Management processes

The proposed IT Project Complexity Management framework consists of 5 processes (Erro! A origem da referência não foi encontrada.). The processes and steps interact with each other and with other management processes, are incremental and iterative.

1. Plan IT project complexity management: red-flagging complex projects, and deciding management strategies and tools.

2. Identify IT project complexity: listing the project complexity elements, i.e. detection and description of the problem.

3. Analyze IT project complexity: understanding the problem.

4. Plan IT project complexity response strategy: developing options and actions to enhance and use positive complexity, and to reduce or avoid negative complexity. It involves modeling and design of potential solutions. 
5. Monitor and Control IT project complexity: the process of implementing response strategies, monitoring, controlling, and evaluating the overall effectiveness. It is a continuous activity.

The traditional methodologies for problem management require a 2-step process for problem understanding: a) identification and b) analysis (PMI, 2017) (Marle \& Vidal, 2016). Complexity theory assumes strong structural variety and interdependence of the system's elements, as well as ambiguity and dynamic phenomena, therefore the identification and analysis of complexity cannot be performed in independent consecutive steps; they are intertwined.

Planning and understanding activities are done at the beginning of a project, but all activities are ubiquitous throughout all project phases. Throughout the project, the project manager should continue to understand project complexity better, by identifying additional complexity elements, and by analyzing and re-analyzing project complexity; replan and re-evaluate the process results. We propose therefore an iterative approach, where results of each step constitute valuable input to both subsequent, as well as previous steps.

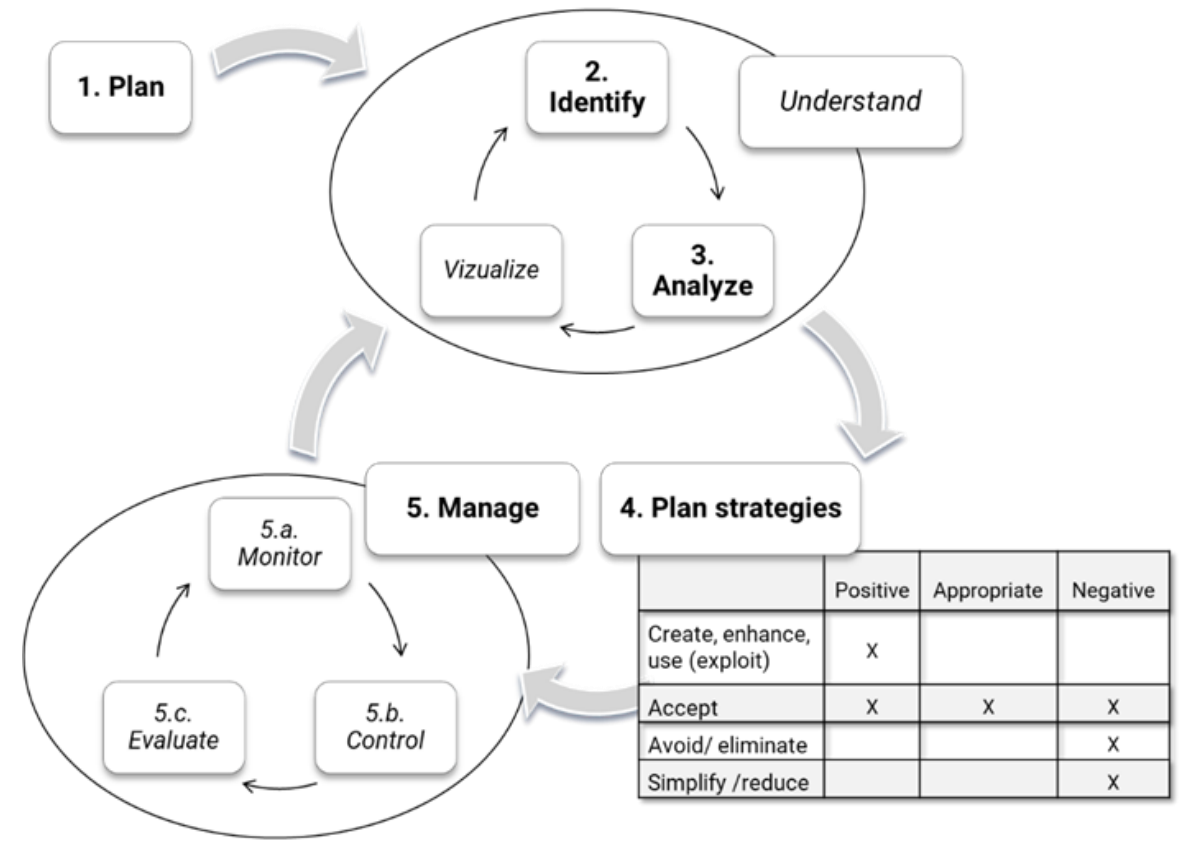

Figure 2. IT Project Complexity Management Framework - overview

Planning is performed at the beginning of the project, typically at the project approval gates: during the feasibility study, and/or project planning. The planning process includes: a) measuring/assessing the complexity level; red-flag the project if complex, with measurement tools such as the Crawford-Ishikura Factor Table for Evaluating Roles CIFTER, Vidal's Analytic Hierarchy Process, Hass' Project Complexity Model Formula (Morcov, et al., 2020a); and b) deciding if complexity should be managed specifically, and how, by choosing from the list of available tools at the disposal of the project manager. The decision of the tools and methods should be based on a cost-benefit analysis.

There are 2 specific moments when complexity assessment is particularly important: the initial go/no-go decision to start a project, and during the project planning phase.

Identification and analysis focus on objective, structural complexity, because structural complexity is less abstract, thus more discussable, analyzable, measurable, and manageable.

Qualitative analysis categorizes complexity based on effects, as positive, appropriate, or negative, e.g. using the Complexity Effect Scale - CES tool (Morcov, et al., 2020b). This analysis should be done primarily against the initial project objectives. Of course, the project objectives will be adapted, if new opportunities are uncovered during this analysis (PMI, 2017). Quantitative analysis can help prioritize and thus select the most useful subset of complexity items and tools to be applied. It includes quantifying the elements of complexity in numeric values, such as financial impact; similarly to the quantitative analysis of risks. It supports the application of numeric tools such as cost-benefit and Pareto. Visualizing IT project 
complexity is a general tool for analysis, especially suitable for engineering projects. System views help visualize both structural complexity and dynamic complexity.

The analysis relies on decomposition, which can be too granular, thus inefficient, or too superficial, thus not useful. A rule-of-thumb for deciding if an analysis is sufficiently detailed can be: Detail until you know what is to be done.

The potential strategies for complexity management (Figure 3) are designed based on the consideration that complexity is not always negative; that some elements of complexity are necessary and even produce positive effects. Traditionally, both research and practice focus on the negative effects of complexity, on the relationship between complexity, risk, and failure. Still, the complexity of IT projects and products is sometimes appropriate; and even positive. Complexity is needed to ensure system viability; it enhances creativity and innovation; offers functionality (Beer, 1972) (McKelvey \& Boisot, 2009) (Floricel, et al., 2016) (Maurer, 2017). Appropriate (requisite) complexity is needed for the project to reach its objectives; its contribution to project success balances the negative effects. Positive complexity adds value to a project; its contribution to project success outweighs the associated negative consequences. Since it creates opportunity, it should be exploited rather than eliminated. Appropriate (requisite) and positive complexity are similar to the opportunities of risk management, and to antifragility (McKelvey \& Boisot, 2009) (PMI, 2017) (Taleb, 2012).

\begin{tabular}{|l|l|c|c|c|}
\hline & \multirow{2}{*}{ Response strategy } & \multicolumn{3}{|c|}{ Complexity Effect } \\
\cline { 3 - 5 } & Positive & Appropriate & Negative \\
\hline a. & Create, enhance & $\mathrm{x}$ & & \\
\hline b. & Use (exploit) & $\mathrm{x}$ & $\mathrm{x}$ & $\mathrm{x}$ \\
\hline c. & Accept / ignore & & & $\mathrm{x}$ \\
\hline d. & Simplify / reduce & & & $\mathrm{x}$ \\
\hline e. & Avoid / eliminate & & & \\
\hline
\end{tabular}

Figure 3. The Mitigation Strategies Matrix - MSM (Morcov, et al., 2020b)

Complexity-related phenomena in one sub-system could lead to opposite effects in another sub-system, because of propagation phenomena (Marle \& Vidal, 2016). Also, complex IT projects are emergent and dynamic, which requires a different paradigm than in a deterministic environment, since the project plan is known to be subject to change as it unfolds; not all activities can be foreseen; not all methods and objectives are known (Daniel \& Daniel, 2018). Therefore, similarly as argued above regarding understanding and analyzing complexity, the plan should be detailed until it is clear what has to be done; but the level of detail required for a project plan is different for the different phases in a project lifecycle. The wave-crest planning model can support such an approach, where the activities of the near future are much more detailed than the activities planned for the distant future. This paradigm is a common practice in software engineering, which has long faced issues of complexity including uncertainty in methods and objectives, and has systematically experimented with and adopted flexible models, e.g. iterative, incremental, and agile development.

The process of monitoring, controlling, implementing response strategies, and evaluating the overall effectiveness is a continuous activity performed throughout the project's life, as part of a Monitoring and Controlling Process Group. The proposed inventory of tools focuses on objective, structural complexity, because structural complexity is less abstract, thus more discussable, measurable, and manageable. Dynamic complexity aspects are related to "unknown unknowns"; difficult to identify or plan. They behave like Black Swans and follow "Butterfly Effect" patterns (Lorenz, 1963) (Taleb, et al., 2009). Still, dynamic complexity aspects must be monitored, recognized, and identified as they occur, and the project should be prepared to deal with them. The main tool, in this case, is monitoring for change, especially in stakeholders, objectives, and the environment.

Table 1 and Figure 4 offer an overview of the proposed IT project complexity management framework, with inputs, outputs, tools and techniques, per phase. 
IT Project Complexity Management overview

\begin{tabular}{|l|}
\hline 1. Plan IT project complexity \\
management \\
\hline 1. Inputs \\
Scope statement \\
Risk management plan \\
Communication management \\
plan \\
Schedule management plan \\
Cost management plan \\
Enterprise environmental \\
factors \\
2. Outputs \\
Project complexity \\
measurement/red-flag \\
Complexity management plan \\
.3. Tools \& Techniques \\
Complexity measurement tools \\
\hline
\end{tabular}

\section{Analyse IT project} complexity

.1. Inputs

Complexity register

Risk register

Stakeholder register

Project management plan

Scope, schedule, cost,

communication management

plans

.2. Outputs

Complexity Register updates

Positive/appropriate/negative complexity classification

Complexity and system

diagrams

.3. Tools \& Techniques

CES, COSM

Cause analysis, Pareto, cost-

benefit

Expert judgment

Use-case analysis

Visualization tools: diagrams,

Goals-and-methods, mapping:

DSM, DMM, MDM, Causal-loop,

Process and workflow

diagrams, UML, SoaML, SysML

\section{Identify IT project complexity}

\section{.1. Inputs}

Scope statement

Stakeholder register

Schedule baseline

Risk register

Enterprise environmental

factors

2. Outputs

Complexity Register

3. Tools \& Techniques

Checklists and classifications

of project complexity

CES, COSM

Risk and vulnerability

identification methods

Breakdown Structures

Expert judgment

\section{Plan IT project complexity} response strategy

1. Inputs

Complexity Register

Complexity management plan

Organizational assets

Market information

\section{.2. Outputs}

Complexity Register updates

Decisions regarding contract

management, schedule, project

objectives

Updates to scope statement,

Project management plan,

Communication plan

.3. Tools \& Techniques

Response strategies for

positive and negative

complexity: Mitigation

Strategies Matrix - MSM

Expert judgment

\begin{tabular}{|l|}
\hline $\begin{array}{l}\text { 5. Monitor and Control IT } \\
\text { project complexity }\end{array}$ \\
\hline 1. Inputs \\
Complexity Register, Risk \\
register \\
Performance reports, project \\
performance information, \\
project management \\
performance information \\
Stakeholder registers \\
Scope statement, initial \\
assumptions \\
2. Outputs \\
Complexity Register updates \\
Updates to Scope statement, \\
Communication plan, Project \\
management plan, Project \\
documents \\
3. Tools \& Techniques \\
Audits and reviews, Status \\
meetings \\
Monitor for change in project, \\
product, processes, \\
organization, market; in \\
stakeholders and interests, \\
objectives, scope; environment. \\
Complexity management \\
response strategies \\
Program management \\
EVM, AgileEVM \\
Role definition \\
Complexity measurement and \\
evaluation tools \\
\end{tabular}

Figure 4. IT Project Complexity Management processes, inputs, outputs, tools and techniques

Table 1. IT Project Complexity Management framework, with inputs, outputs, tools and techniques, per phase

\begin{tabular}{|l|l|l|}
\hline Inputs & Outputs & Tools and techniques \\
\hline 1. Plan IT project complexity management & \multicolumn{2}{|l|}{} \\
\hline Scope statement & Red-flag project as & Complexity measurement and evaluation tools (Morcov, et al., \\
Risk management plan & complex (complexity & 2020a): CIFTER scale, Hass, \\
Communication, schedule, & measurement) & Vidal AHP scale, Morcov scale \\
cost management plans & Complexity & Simple, complicated, complex, really complex projects \\
Enterprise environmental & management plan & (Hertogh \& Westerveld, 2010) (Bakhshi, et al., 2016). \\
factors & & \\
& & \\
\end{tabular}




\begin{tabular}{|c|c|c|}
\hline \multicolumn{3}{|c|}{ 2. Identify IT project complexity } \\
\hline $\begin{array}{l}\text { Scope statement, scope } \\
\text { baseline } \\
\text { Stakeholder register, } \\
\text { communications } \\
\text { management plan } \\
\text { Schedule management } \\
\text { plan, schedule baseline } \\
\text { Risk management plan, } \\
\text { risk register } \\
\text { Project documents } \\
\text { Market analysis } \\
\text { Enterprise environmental } \\
\text { factors }\end{array}$ & Complexity Register & $\begin{array}{l}\text { Checklists and classifications of project complexity (Morcov, et } \\
\text { al., 2020a) such as: } \\
\text { - } \quad \text { Technical vs. organizational complexity (Baccarini, 1996) } \\
\text { - } \quad \text { Related to ambiguity, uncertainty, propagation, or chaos; } \\
\text { related to size, variety, interdependence, or context (Marle } \\
\text { \& Vidal, 2016) } \\
\text { - Market, organization, process, product (Maurer, 2017) } \\
\text { - } \quad \text { Task-related complexity (business, external, organizational } \\
\text { complexity) vs. system-related complexity (technological } \\
\text { complexity) } \\
\text { TOE model - technological, organizational, environmental } \\
\text { complexity (Bosch-Rekveldt, et al., 2011) } \\
\text { Checklists of complexity indicators, dimensions, measures } \\
\text { Complexity Effect Scale tool - CES, Complexity Source/Effect } \\
\text { Segmentation Matrix tool - COSM (Morcov, et al., 2020b) } \\
\text { Risk and vulnerability identification methods, SWOT analysis, } \\
\text { WWWWHW, analysis of PEST, STEEP, STEEPLE, PERSI } \\
\text { factors, Balanced Scorecard (Marle \& Vidal, 2016) } \\
\text { Systems engineering analysis (Maurer, 2017) } \\
\text { X-BS: WBS Work Breakdown Structure, Risk BS, Resource } \\
\text { BS, Product BS, Organization BS (Levine, 1993) } \\
\text { Reference-class forecasting } \\
\text { Audits, documentation reviews, assumptions analysis, Market } \\
\text { analysis tools, External audits, Expert judgment }\end{array}$ \\
\hline Inputs & Outputs & Tools and techniques \\
\hline \multicolumn{3}{|c|}{ 3. Analyse IT project complexity } \\
\hline $\begin{array}{l}\text { Complexity register } \\
\text { Risk register } \\
\text { Stakeholder register } \\
\text { Project management plan } \\
\text { Scope, schedule, cost, } \\
\text { communication } \\
\text { management plans }\end{array}$ & $\begin{array}{l}\text { Complexity Register } \\
\text { updates } \\
\text { Positive/appropriate/ } \\
\text { negative complexity } \\
\text { classification } \\
\text { Complexity and } \\
\text { system diagrams }\end{array}$ & $\begin{array}{l}\text { Quantitative \& qualitative analysis of complexity effects and } \\
\text { sources: CES, COSM } \\
\text { Complexity measurement and evaluation tools - as checklists } \\
\text { Root-cause analysis, fault-tree; cause-and-effect diagrams, } \\
\text { Ishikawa, problem-tree, Toyota 5-Why's, Pareto, use-case } \\
\text { analysis } \\
\text { Cost-benefit analysis } \\
\text { Project Systemic Vulnerability Analysis } \\
\text { Market analysis tools, Delphi, focus groups, affinity diagrams, } \\
\text { brainstorming } \\
\text { Checklists, Expert judgment } \\
\text { Complexity visualization tools: } \\
\text { Diagramming techniques, system views help visualize both } \\
\text { structural complexity and dynamic complexity } \\
\text { Goals-and-methods matrix (Turner \& Cochrane, 1993) } \\
\text { Complexity mapping diagram (Remington \& Pollack, 2007), } \\
\text { dependency modelling, DSM, DMM (Maurer, 2017), MDM } \\
\text { (Marle \& Vidal, 2016) } \\
\text { Causal-loop diagrams - Systems Thinking } \\
\text { Use-case analysis, Graphs, mind-maps, UML, SoaML, SysML }\end{array}$ \\
\hline \multicolumn{3}{|c|}{ 4. Plan IT project complexity response strategy } \\
\hline $\begin{array}{l}\text { Complexity Register } \\
\text { Complexity management } \\
\text { plan } \\
\text { Organizational assets } \\
\text { Market information }\end{array}$ & $\begin{array}{l}\text { Decisions and } \\
\text { updates to } \\
\text { Complexity Register, } \\
\text { scope \& objectives, } \\
\text { schedule, PM \& } \\
\text { communication plans }\end{array}$ & $\begin{array}{l}\text { Response strategies for positive and negative complexity: } \\
\text { Mitigation Strategies Matrix - MSM (Morcov, et al., 2020b) } \\
\text { - Create, enhance, use (exploit): positive complexity } \\
\text { - Accept: positive, appropriate, or negative complexity } \\
\text { - Avoid/ eliminate, simplify /reduce: negative complexity } \\
\text { Expert judgment }\end{array}$ \\
\hline
\end{tabular}




\begin{tabular}{|c|c|c|}
\hline \multicolumn{3}{|c|}{ 5. Monitor and control IT project complexity } \\
\hline \multicolumn{3}{|l|}{ 5.a. Monitor } \\
\hline $\begin{array}{l}\text { Complexity Register } \\
\text { Risk register } \\
\text { Performance reports } \\
\text { Change register \& } \\
\text { requests, configuration } \\
\text { Stakeholder registers } \\
\text { Scope statement \& initial } \\
\text { assumptions }\end{array}$ & $\begin{array}{l}\text { Complexity Register } \\
\text { updates }\end{array}$ & $\begin{array}{l}\text { Audits and reviews } \\
\text { Status meetings } \\
\text { Monitor for change (Whyte, et al., 2016): } \\
\text { - in project, product, processes, organization, market. } \\
\text { - in stakeholders and stakeholders' interests, project } \\
\quad \text { objectives, and scope; environment. } \\
\text { COSM } \\
\text { Recheck assumptions }\end{array}$ \\
\hline \multicolumn{3}{|l|}{ 5.b. Control } \\
\hline Complexity Register & $\begin{array}{l}\text { Updates to } \\
\text { Complexity Register, } \\
\text { Scope statement } \\
\text { (change requests), } \\
\text { communication plan, } \\
\text { PM plan }\end{array}$ & $\begin{array}{l}\text { Implement complexity management response strategies } \\
\text { Implement the project as a program (Remington \& Pollack, } \\
\text { 2007) } \\
\text { Earned Value Management EVM (PMI, 2017) } \\
\text { AgileEVM (Sulaiman \& Smits, 2007) } \\
\text { Integrating uncertainty into EVM (Pajares \& López-Paredes, } \\
\text { 2011). } \\
\text { Role definition (Remington \& Pollack, 2007) }\end{array}$ \\
\hline \multicolumn{3}{|r|}{ 然 } \\
\hline $\begin{array}{l}\text { Complexity Register } \\
\text { Performance reports }\end{array}$ & $\begin{array}{l}\text { Complexity } \\
\text { management plan } \\
\text { updates }\end{array}$ & $\begin{array}{l}\text { Audits and reviews } \\
\text { Complexity measurement and evaluation tools }\end{array}$ \\
\hline
\end{tabular}

\section{CONCLUSION}

This paper proposes a conceptual framework for IT Project Complexity Management, in which individual specific processes and tools can be anchored and applied in a structured way.

The processes and steps interact with each other and with other project management processes; they overlap, are incremental and iterative. An inventory of tools and methods is proposed for each process and step in the framework. The inventory of potential tools and methods is not and cannot be exhaustive nor definitive; as all inventories of tools, it is a starting point: additional potential tools are continuously proposed; some tools are duplicated or are similar; there are different tools with the same name or similar tools with different names.

Complexity management contributes to the success of IT projects, reduces project risk, helps better project understanding, allows for better prioritization and planning of resources. The proposed framework aims to support practitioners to recognize, understand, analyze, and manage complexity more effectively, thus reducing associated risks and increasing project success rates. As with any tool or method, each organization and project manager should decide when and to what degree to apply a specific framework or set of tools to a particular portfolio or project.

\section{REFERENCES}

Allen, M. \& Sites, R., 2012. Leaving ADDIE for SAM: An agile model for developing the best learning experiences. American Society for Training \& Development.

Australian Government, Department of Defence, 2012. Defence capability plan - public version. [Online] Available at: http://www.defence.gov.au/publications/docs/CapabilityPlan2012.pdf [Accessed 19 May 2019].

Baccarini, D., 1996. The concept of project complexity, a review. International Journal of Project Management, 14(4), pp. 201-204.

Bakhshi, J., Ireland, V. \& Gorod, A., 2016. Clarifying the project complexity construct: Past, present and future. International Journal of Project Management, Volume 34, p. 1199-1213.

Beer, S., 1972. Brain of the Firm. London: The Penguin Press.

Bjorvatn, T. \& Wald, A., 2018. Project complexity and team-level absorptive capacity as drivers of project management performance. International Journal of Project Management, Volume 36, p. 876-888.

Bosch-Rekveldt, M. et al., 2011. Grasping project complexity in large engineering projects: the TOE (Technical, Organizational and Environmental) framework. International Journal of Project Management, Volume 29, p. 728-739.

Botchkarev, A. \& Finnigan, P., 2015. Complexity in the Context of Information Systems Project Management. Organisational Project Management, 2(1), pp. 15-34. 
Boyd, J., 2018. A Discourse on Winning and Losing. Maxwell AFB, Alabama: Air University Press.

Daniel, P. A. \& Daniel, C., 2018. Complexity, uncertainty and mental models: From a paradigm of regulation to a paradigm of emergence in project management. International Journal of Project Management, Volume 36, p. 184-197.

Davies, A., Dodgson, M., Gann, D. \& Macaulay, S., 2017. Five Rules for Managing Large, Complex Projects. MIT Sloan Management Review, 59(1), pp. 73-78.

Floricel, S., Michel, J. L. \& Piperca, S., 2016. Complexity, uncertainty-reduction strategies, and project performance. International Journal of Project Management, Oct, 34(7), pp. 1360-1383.

GAPPS, 2007. A Framework for Performance Based Competency Standards for Global Level 1 and 2 Project Managers. Sydney: Global Alliance for Project Performance Standards.

Głodziński, E., 2019. Performance measurement of complex project: framework. International Journal of Information Systems and Project Management, 7(2), pp. 21-34.

Gummesson, E., 2000. Qualitative Methods in Management Research. London: Sage.

Hertogh, M. \& Westerveld, E., 2010. Ph.D. thesis: Playing with Complexity - Management and organisation of large infrastructure projects. s.1.:s.n.

Kitchenham, B., 2004. Procedures for Performing Systematic Reviews, Keele, Staffs: Keele University.

Levine, H. A., 1993. Doing the weebis and the obis: new dances for project managers?. PM Network, 7(4), p. 35-38.

Levitt, H. et al., 2018. Journal Article Reporting Standards for Qualitative Primary, Qualitative Meta-Analytic, and Mixed Methods Research in Psychology: The APA Publications and Communications Board Task Force Report. American Psychologist, 73(1), pp. 26-46.

Liker, J. \& Franz, J., 2011. The Toyota Way to Continuous Improvement: Linking Strategy and Operational Excellence to Achieve Superior Performance. s.l.:McGraw-Hill Education.

Lorenz, E. N., 1963. Deterministic Nonperiodic Flow. Journal of the Atmospheric Sciences, March, 20(2), p. $130-141$.

Marle, F. \& Vidal, L.-A., 2016. Managing Complex, High Risk Projects - A Guide to Basic and Advanced Project Management. London: Springer-Verlag.

Maurer, M., 2017. Complexity Management in Engineering Design - a Primer. Berlin, Heidelberg: Springer Berlin Heidelberg.

McKelvey, B. \& Boisot, M., 2009. Redefining strategic foresight: 'Fast' and 'far' sight via complexity science. L.A. Costanzo and R.B. MacKay (eds) Handbook of Research on Strategy and Foresight. Cheltenham, UK: Elgar, p. 15-47.

Montequín, V. R., Joaquín, V. B., Sonia María, C. F. \& Francisco, O. F., 2018. Exploring project complexity through project failure factors: Analysis of cluster patterns using self-organizing maps. Complexity, p. 17.

Morcov, S., Pintelon, L. \& Kusters, R. J., 2020a. Definitions, characteristics and measures of IT Project Complexity - a Systematic Literature Review. International Journal of Information Systems and Project Management, 8(2), pp. 5-21.

Morcov, S., Pintelon, L. \& Kusters, R. J., 2020b. IT Project Complexity Management Based on Sources and Effects: Positive, Appropriate and Negative. Proceedings of the Romanian Academy - Series A, 21(4), pp. 329-336.

Pajares, J. \& López-Paredes, A., 2011. An extension of the EVM analysis for project monitoring: The cost control index and the schedule control index. International Journal of Project Management, 29(5), p. 615-621.

Patanakul, P., 2014. Managing large-scale IS/IT projects in the public sector: Problems and causes leading to poor performance. Journal of High Technology Management Research, p. 21-35.

Peffers, K., Tuunanen, T., Rothenberger, M. \& Chatterjee, S., 2007. A design science research methodology for information systems research. Journal of Management Information Systems, pp. 45-77.

PMI, 2013. Pulse of the Profession In-Depth Report: Navigating Complexity, s.1.: s.n.

PMI, 2014. Navigating Complexity: A Practice Guide. Newtown Square, PA: Project Management Institute.

PMI, 2017. A Guide to the Project Management Body of Knowledge (PMBOK Guide), Sixth Edition. Pennsylvania: Project Management Institute.

Remington, K. \& Pollack, J., 2007. Tools for complex projects. London: Gower Publishing Ltd.

Riis, J. O. \& Pedersen, F. L., 2003. Managing organizational development projects by paradoxes. Production Planning \& Control, 14(4), p. 349-360.

Satzinger, J. W., Jackson, R. B. \& Burd, S., 2007. Systems Analysis \& Design In A Changing World. Boston: Thomson Course Technology.

Schwaber, K. \& Sutherland, J., 2020. The 2020 Scrum Guide. [Online] Available at: https://www.scrumguides.org/scrum-guide.html [Accessed 27 Dec 2020].

Sulaiman, T. \& Smits, H., 2007. Measuring Integrated Progress on Agile Software Development Projects. Methods \& Tools, 15(3), pp. 2-9.

Taleb, N. N., 2012. Antifragile: things that gain from disorder. New York: Random House.

Taleb, N. N., Goldstein, D. G. \& Spitznagel, M. W., 2009. The Six Mistakes Executives Make in Risk Management. Harvard Business Review.

Turner, J. \& Cochrane, R., 1993. Goals-and-methods matrix: coping with projects with ill defned goals and/or methods of achieving them. International Journal of Project Management, 11(2), pp. 93-102.

Whyte, J., Stasis, A. \& Lindkvist, C., 2016. Managing change in the delivery of complex projects: Configuration management, asset information and 'big data'. International Journal of Project Management, 34(2), p. 339-351. 